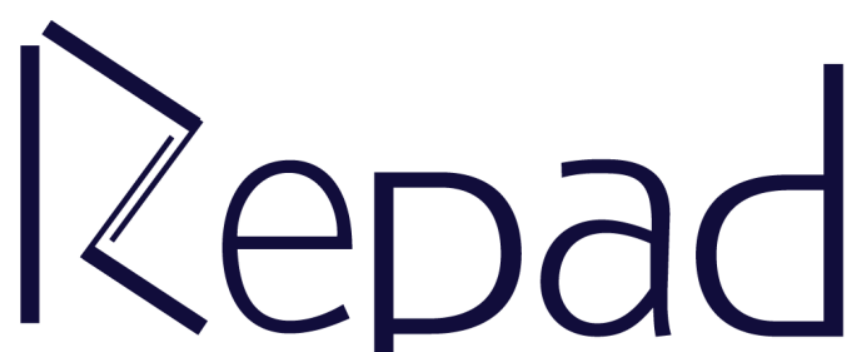

vol. 3, n. 3, Setembro-Dezembro/2019

Revista Estudos e

Pesquisas em Administração 


\title{
CAPITAL INTELECTUAL E GESTÃO DO CONHECIMENTO: Percepção dos funcionários da holding de um grupo de empresas goianas
}

\author{
José Julio de Siqueira Sartori \\ Centro Universitário Alves Faria, Goiânia, Goiás, Brasil \\ Brasilia04@hotmail.com \\ https://orcid.org/0000-0003-2437-5037 \\ Herica Landi de Brito \\ Centro Universitário Alves Faria, Goiânia, Goiás, Brasil \\ herica.landi@unialfa.com.br \\ https://orcid.org/0000-0002-0629-5634
}

\section{Resumo}

O objetivo do presente estudo foi avaliar as práticas de capital intelectual e de gestão do conhecimento da holding de um grupo de empresas de Goiás, na perspectiva de seus funcionários. Participaram 100 funcionários que responderam aos seguintes instrumentos validados no Brasil: Escala de Classificação do Capital Intelectual e Escala de Gestão do Conhecimento. Constatou-se que, dentre os três elementos que compõem o Capital Intelectual, sendo Capital Humano, Capital Estrutural e Capital Relacional, o melhor avaliado foi o Capital Estrutural $(\mathrm{M}=4,0)$ e o menos avaliado foi o Capital Humano (M = 3,3). Em relação à Gestão do Conhecimento, o fator mais bem avaliado foi a Orientação Cultural para o Conhecimento $(\mathrm{M}=4,0)$ e o menos avaliado foi Práticas Formais de Gestão do Conhecimento $(M=3,5)$. Enfatizou-se a importância da implementação estratégica de uma gestão focada no conhecimento, alinhada a objetivos e estratégias organizacionais, para agregar valor aos clientes internos e externos. Limitações e sugestões de novos estudos foram descritas.

Palavras-chaves: Capital Intelectual; Gestão do Conhecimento; Avaliação.

\section{INTELLECTUAL CAPITAL AND KNOWLEDGE MANAGEMENT: Perception of the employees of the holding of a group of Goias companies}

\begin{abstract}
The objective of the present study was to evaluate the intellectual capital and knowledge management practices of the holding of a group of companies from Goiás, from the perspective of their employees. Participants were 100 employees who answered the following validated instruments in Brazil: Intellectual Capital Rating Scale and the Knowledge Management Scale. It was found that, among the three elements that make up Intellectual Capital, being Human Capital, Structural Capital and Relational Capital, the best evaluated was Structural Capital $(M=4.0)$ and the least evaluated was Human Capital ( $\mathrm{M}=3.3)$. Regarding Knowledge Management, the best evaluated factor was the Cultural Orientation for Knowledge $(\mathrm{M}=4.0)$ and what was least evaluated was the Formal Knowledge Management Practices $(M=3.5)$. It has been emphasized the importance of the strategic implementation of a management focused on knowledge aligned with the objectives and organizational strategies so that it can add value to internal and external customers. Limitations and suggestion of further studies have been described.
\end{abstract}

Keywords: Intellectual Capital; Knowledge Management; Evaluation. 
Submetido: 30/09/2019

Aceito: 19/11/2019

Publicado: 31/12/2019

\section{INTRODUÇÃO}

Autores têm reconhecido a importância do conhecimento organizacional, enquanto ativo intangível, para a vantagem competitiva sustentável das organizações, na medida em que sua construção, quando associada à história e cultura da empresa, dificulta a replicação pelos competidores (ALVESSON; KARREMAN, 2001; ARGOTE; MCEVILY; REAGANS, 2003; BROWN; DUGUID, 2001; DAVENPORT, 1994).

Nesse sentido, a gestão do conhecimento apresenta relevância estratégica para as organizações por se constituir em um instrumento de manutenção e ampliação de seu capital intelectual que, por sua vez, é constituído por todos os conhecimentos de uma empresa (DAVENPORT; DE LONG; BEERS, 1998).

Desta forma, práticas de gestão do conhecimento podem ser definidas como práticas organizacionais interdependentes relacionadas à criação, retenção/recuperação do conhecimento, transferência do conhecimento e aplicação de conhecimento em seus processos, produtos e serviços da organização. De modo geral, tais práticas apresentam como objetivo principal a capacitação das organizações para atingirem resultados por meio do compartilhamento do conhecimento entre os indivíduos (ALAVI; LEIDNER; 1999; ALAVI; LEIDNER 2001).

Para tal, as ações empreendidas no âmbito dos referidos processos devem ser estruturadas com base em objetivos organizacionais e, portanto, é necessário que estejam integradas à estratégia da empresa (DAVENPORT, 1998).

Apesar do reconhecimento da importância do capital intelectual como um diferencial competitivo e da relevância do seu gerenciamento para a competitividade organizacional, ainda há poucos estudos empíricos publicados em periódicos científicos que avaliem o Capital Intelectual e a Gestão do Conhecimento, sobretudo no contexto brasileiro. Mais escassos ainda são estudos que avaliem tais variáveis em holdings que se constituem em sociedade estratégica que controla várias empresas (BIANCHINI; GONÇALVES; ECKERT; MECCA, 2014).

Nesse sentido, o presente estudo visa contribuir com a análise e descrição da percepção de funcionários da holding de um grupo de empresas goianas quanto às práticas de gestão do conhecimento desenvolvidas na organização e aos três componentes dos ativos do conhecimento (capital estrutural; capital humano e capital relacional).

A produção textual estrutura-se em cinco seções. A seção 1 apresenta uma fundamentação teórica acerca da gestão do conhecimento e do capital intelectual. A seção 2 descreve os procedimentos metodológicos utilizados para a realização da pesquisa, seu delineamento, instrumentos e técnicas utilizadas na coleta de dados. A seção 3 corresponde à apresentação dos resultados e discussão da pesquisa. E, por fim, na seção 4, apresentam-se as conclusões do estudo. Às seções são seguidas as referências que fundamentaram a presente pesquisa.

\section{REFERENCIAL TEÓRICO}

Com a globalização da economia observa-se um crescente dinamismo e velocidade de informações, tanto no mercado financeiro quanto no comercial, impondo 
novas questões à gestão empresarial, que por sua vez demandam estratégias de adaptação para que as organizações se mantenham competitivas e alinhadas aos padrões internacionais no mundo dos negócios (FEITOSA, 2015; MARQUES; GOMES, 2011).

Diante desse contexto socioeconômico, a capacidade de aprender mais rápido que seus concorrentes, produzirem novos conhecimentos e os geri-los de forma eficaz tornase uma fonte de vantagem competitiva para as organizações contemporâneas nas quais um novo fator estratégico passa a ser gerenciado, visando a permanência da empresa no mercado e expansão de seus negócios agregando valor aos mesmos. Trata-se do capital intelectual (GRACIOLI, 2005).

De acordo com Duffy (2000), o conceito de Capital Intelectual é amplo e abrange os conhecimentos acumulados de uma empresa relativos a pessoas, metodologias, patentes, projetos e relacionamentos. O mesmo é composto pelos seguintes elementos constitutivos: capital humano; capital estrutural e capital relacional.

O Capital Humano refere-se ao valor acumulado de investimentos em treinamento, competência e futuro de um funcionário, bem como a capacidade de relacionamento e valores. Alguns fatores que agregam valor ao capital humano são: know-how, educação, qualificação vocacional, conhecimento relacionado ao trabalho, avaliações ocupacionais, ímpeto para empreender, inovatividade, proatividade, entre outros (DZINKOWSKI, 2000).

O Capital Estrutural inclui a propriedade intelectual em que se encontram as patentes, direitos autorais, direitos de projeto, segredos industriais e marcas registradas e os ativos de infraestrutura compostos pela filosofia gerencial, cultura corporativa, processos gerenciais, sistemas de informação e sistemas de rede. Esse ativo é o somatório dos processos internos das empresas e dela com os seus parceiros externos que é seu capital de processos. Acrescente ainda o relacionamento desenvolvido com seus fornecedores, prestadores de serviços, além de outros parceiros e, por fim, o capital de inovação que é o portfólio da empresa na perspectiva de criar novos conhecimentos. A partir de conhecimentos que a organização já detém são observados os aspectos internos da própria corporação, representados pela tecnologia, cultura, forma de organização, além da gestão corporativa (DZINKOWSKI, 2000).

O Capital Relacional refere-se aos relacionamentos contínuos com as pessoas e organizações para as quais a empresa vende os seus produtos e serviços. Somam-se também as relações com o exterior da empresa, seus acionistas, clientes, instituições e fornecedores (STEWART, 1998).

Por sua vez, Edvinsson e Malone (1998) dividem o capital estrutural em três categorias que são: 1. Capital Organizacional: abrange o investimento que a empresa faz em sistemas, instrumentos e filosofia operacional para agilizar o fluxo de conhecimento dentro da organização; 2. Capital de Inovação: refere-se à capacidade de renovação e inovação e encontram-se na forma de direitos comerciais, propriedade intelectual, outros ativos e valores intangíveis, como conhecimentos, receitas e segredos de negócios; 3. Capital de Processos: constituído por processos, técnicas (exemplo: ISSO 9000; ISSO 14001) e programas direcionados aos empregados com o objetivo de aumentar e ampliar a eficiência da produção ou da prestação de serviços.

Os fatores que compõem o capital intelectual, quando gerenciados de maneira eficiente, geram capacidade produtiva que é evidenciada através da inovação e reestruturação contínua dos processos, gerando resultados satisfatórios para as organizações, pois conhecimento e informação são ativos para as empresas. As maiores chances de crescer e sobreviver são determinadas pelas inovações de produtos e serviços 
que essa organização for capaz de criar, por meio do conhecimento dos seus colaboradores (GOMES, 2014; MOREIRA; VIOLIN; SILVA, 2014).

Segundo Gomes (2014), os ativos intelectuais são a principal ferramenta para a criação de valor e competitividade nas atividades da empresa. As organizações que sabem utilizar seu capital intelectual tornam-se mais bem sucedidas, criando novas formas e fórmulas de inovar-se tendo a criatividade e competitividade como molas propulsoras de suas decisões e ações para criação de valor. Portanto, a organização não deve retê-lo ou se limitar a proporcioná-lo apenas aos gestores, pois o conhecimento deve ser difundido e as informações compartilhadas. Ou seja, para que uma empresa possa manter essa vantagem competitiva no mercado, ela precisa administrar o conhecimento que possui (GREGOLIN, 2016; MARQUES; GOMES, 2011).

Nesse sentido, de acordo com Pais (2014), a gestão do conhecimento configura a capacidade de uma dada organização para criar/adquirir conhecimento, disseminá-lo e incorporá-lo aos seus processos, produtos e serviços. Assim, ações conducentes à criação, partilha e utilização do conhecimento são cruciais e determinantes do sucesso da gestão que é feita com a colaboração do conhecimento organizacional.

Dessa forma, a gestão do conhecimento procura preencher duas das lacunas das organizações que são: mensurar o capital intelectual existente dentro das empresas e promover estratégias no sentido de colocá-lo a serviço da organização, por meio de ferramentas substanciais de disseminação interna do conhecimento com vistas a tornar as empresas mais competitivas (RODRIGUES et al., 2015).

De acordo com Pires, Menegassi e Tatto (2016), a incorporação da Gestão do Conhecimento dos processos internos das empresas tem por finalidade assegurar os ativos intangíveis de uma organização, como também dar-lhe capilaridade e aproveitá-los, fomentando a criação de serviços e produtos direcionados às necessidades dos clientes e ao incremento da competitividade. Nesse sentido, tem como objetivo democratizar o acesso aos conhecimentos obtidos pelos colaboradores organizando, classificando e criando oportunidades de disseminação desse capital intelectual.

Colauto e Beuren (2003) destacam a importância de se intensificar a aquisição e o gerenciamento do conhecimento humano e a aprendizagem interativa contínua dentro das organizações, para que elas possam manter um diferencial competitivo nessa era da informação. A organização transfere seu patrimônio de conhecimentos para as pessoas, preparando-as para enfrentar novas situações profissionais e pessoais, quer na organização ou fora dela. As pessoas, por sua vez, ao desenvolverem sua capacidade individual, transferem para a organização seu aprendizado, capacitando a organização para enfrentar novos desafios (ARMOS, 2003; DUTRA, 1999).

O acúmulo de conhecimentos gerado pelos colaboradores de uma empresa tornase uma das fontes de vantagem, na medida em que ela consegue utilizar esse capital a seu favor, garantindo a inovação de seus produtos e serviços tendo como base a criação do conhecimento, o seu compartilhamento colaborativo e seu gerenciamento sistemático (PIRES et al., 2016).

As informações agregadas pelos seus colaboradores devem transformar-se em conhecimentos que possibilitem extirpar as ameaças e valorizar as oportunidades, presentes em seu meio ambiente interno e externo, por meio de ações que desencadeiem o crescimento contínuo da empresa. Essas ações devem, necessariamente, passar pelo suporte da tecnologia, pela utilização e valorização do capital intelectual e pela gestão do conhecimento, para que, em conjunto, auxiliem a avaliação e a remodelação dos 
processos, procurando sempre melhorar a produtividade e as vantagens competitivas (EDVINSSON; MALLONE, 1998).

Sendo assim, é imprescindível que sejam feitas medições, ainda que experimentais, acerca dos ativos do conhecimento e de sua gestão que podem, inclusive, traduzirem-se em uma maior valorização do ativo organizacional (NASCIMENTO, 2008). De acordo com Armos (2003), iniciativas de mensuração do capital intelectual podem contribuir para o aumento do potencial informativo da contabilidade, redimensionar o patrimônio da organização, canalizar os recursos para investir no capital humano e no capital estrutural, captar investidores, executar uma melhor gestão do conhecimento e gerar lucros.

No entanto, ainda há poucos estudos empíricos publicados em periódicos científicos que avaliam o Capital Intelectual e a Gestão do Conhecimento, sobretudo no contexto brasileiro. Mais escassos ainda são os estudos que avaliam tais variáveis em holdings que se constituem em sociedades estratégicas e importantes que controlam várias empresas e que podem usufruir de mecanismos legais que permitem proteger o patrimônio, direcionar a sucessão hereditária e promover a economia de impostos (BIANCHINI et al., 2014).

Diante do reconhecimento da importância do capital intelectual como um ativo intangível diferencial e a relevância do seu gerenciamento para a competitividade organizacional, o objetivo do presente estudo é avaliar o capital intelectual e as práticas de gestão de conhecimento da holding de um grupo de empresas goianas, a partir da perspectiva de seus colaboradores.

\section{MÉTODO}

\section{Delineamento do estudo}

Trata-se de uma pesquisa de natureza quantitativa, caracterizando-se como um estudo de corte transversal, de caráter descritivo (MARCZYK; DEMATTEO; FESTINGER, 2005).

\section{Participantes}

Participaram desta pesquisa 100 colaboradores (aproximadamente 80\% dos 126 funcionários efetivos) da holding de um grupo empresarial goiano que atua nos segmentos industrial, de serviços e imobiliário há 55 anos, fundada em 1995. Os critérios para a inclusão dos participantes no estudo foram: (a) participação voluntária com assinatura do Termo de Consentimento Livre e Esclarecido (TCLE); (b) ser funcionário da holding independentemente do cargo ou tempo de serviço na organização; (c) idade igual ou acima de 18 anos; (d) ter condições para responder aos instrumentos de autorrelato, sozinho ou com ajuda de pesquisador treinado. Constituíram fatores para exclusão da participação no estudo: (a) funcionários que estavam de férias; (b) de licença médica; (c) em viagem de trabalho ou (d) fora da empresa durante o período de aplicação dos questionários.

\section{Instrumentos de coleta de dados}

Para a coleta de dados foram utilizados três instrumentos:

- Questionário sociodemográfico: elaborado com o objetivo de caracterizar os participantes quanto aos seguintes aspectos: sexo, idade, escolaridade, 
situação conjugal, número de filhos, cargo exercido e tempo de vínculo empregatício na organização.

- Questionário de avaliação do Capital Intelectual: instrumento elaborado por Alves et al.(2014), composto de 22 questões que visam avaliar o capital intelectual, considerando as seguintes categorias: iniciativas para o desenvolvimento do capital humano, iniciativas para o desenvolvimento do capital estrutural e iniciativas para o desenvolvimento do Capital Relacional. Para medir a confiabilidade dos resultados alcançados neste estudo, tendo como base a escala de fatores que avaliaram o Capital Intelectual, utilizou-se o coeficiente Alpha de Cronbach. Para um total de 23 itens, utilizando 100 participantes, o valor alcançado foi de 0,97 , o que se considera como uma consistência Quase Perfeita. Especificamente, o Capital Humano apresentou índice de confiabilidade de 0,88, o Capital Estrutural de 0,96 e o Capital Relacional de 0,96.

- $\quad$ Escala de Gestão do Conhecimento (EGC): trata-se de uma medida de comportamento organizacional focada na gestão de conhecimento elaborado por Pais (2014), com adequação a contextos organizacionais brasileiros ou portugueses. Utilizouse a escala em versão reduzida que contempla 22 itens divididos em quatro fatores, sendo: 1. Orientação cultural para o conhecimento; 2. Orientação competitiva; 3. Práticas formais de Gestão do Conhecimento e 4. Práticas informais de Gestão do Conhecimento. $\mathrm{O}$ primeiro fator remete a uma cultura voltada ao conhecimento na qual é nuclear o valor do conhecimento no sentido de produtividade, da qualidade e da otimização do desempenho organizacional. O segundo fator espelha uma orientação para o exterior por parte da organização, focando na utilização do conhecimento organizacional em uma lógica de competitividade, de desempenho comparativo, dando aos clientes e concorrentes um papel fundamental. O terceiro fator congrega os esforços da organização para o que é relevante conhecer e a adoção de práticas que visam a criação e a aquisição de conhecimento, sua preservação, partilha e utilização, que, em geral, ocorre pela incorporação do conhecimento contido em produtos e serviços. A consciência do conhecimento possibilita a crença e a vontade de conhecer mais e melhor e viabiliza a iniciativa, a improvisação e a inovação. O quarto e último fator traduz-as interações que em âmbito informal ocorrem na organização e que permitem a construção social do conhecimento. Essas interações emergem da prática discursiva e das compreensões coletivas acerca dos conhecimentos organizacionais mais relevantes. No conjunto dos quatros fatores, a escala apresenta um coeficiente de consistência interna de 0,93. Para medir a confiabilidade dos resultados alcançados neste estudo, tendo como base a escala de fatores que avaliaram a Gestão do Conhecimento, utilizou-se o coeficiente Alpha de Cronbach. Para um total de 22 itens, utilizando 100 participantes, o valor alcançado foi de 0,97 , o que se considera como uma consistência quase perfeita.

\section{Procedimentos da coleta e análise de dados}

Inicialmente, o projeto foi apresentado aos diretores responsáveis da holding. Após a autorização da coleta de dados, os participantes foram convidados, pelo pesquisador responsável, a participarem do estudo preservando o sigilo de sua identidade. Mediante a concordância de cada um, foi solicitado que assinassem, antes da aplicação dos instrumentos, o Termo de Consentimento Livre e Esclarecido (TCLE) que formaliza a concordância em participar voluntariamente.

A coleta de dados que foi realizada ocorreu no mesmo dia ou em outros momentos previamente definidos de conveniência do participante, em dia e horário previamente agendados. Antes da aplicação dos questionários, as instruções foram lidas em voz alta e 
uma vez assegurado que os participantes as tivessem compreendido, os instrumentos foram aplicados individualmente e respondidos mediante aplicação assistida. Quando necessário, dúvidas eventuais foram esclarecidas para que todos os itens fossem preenchidos. Foi solicitado ainda que o participante não deixasse nenhuma questão em branco.

Os dados foram computados e analisados no programa Excel, mediante o uso de técnicas descritivas pertinentes aos objetivos do estudo.

Com relação ao material coletado para o estudo de caso, esse será mantido em arquivo físico e digital, resguardados em arquivos, sob a guarda e responsabilidade do autor desta pesquisa, por um período de cinco anos e, uma vez vencido esse prazo, o material físico será incinerado.

\section{RESULTADOS E DISCUSSÃO}

\section{Caracterização Sociodemográfica da amostra}

Participaram do estudo 100 colaboradores, sendo que 64 eram homens (64\%) e 36 eram mulheres (36\%). Os participantes apresentaram idades entre 19 e 76 anos, com média etária geral de 39 anos $(\mathrm{DP}=16$; mediana $=39)$. A escolaridade oscilou entre o ensino fundamental completo (1\%), ensino médio completo (5\%), ensino superior incompleto (17\%) e ensino superior completo (77\%), o que mostra um ótimo nível de escolaridade dentro da empresa.

Os colaboradores casados estão em maior número, são 69\% deles, os solteiros são $25 \%$ e os separados, divorciados ou viúvos são apenas $6 \%$ dos colaboradores. Sobre a existência e a quantidade de filhos, os colaboradores informaram que 64\% deles têm filho e $36 \%$ não têm. Sendo que $3 \%$ possuem quatro filhos, $13 \%$ têm três filhos, $32 \%$ colaboradores declararam ter dois filhos e $52 \%$ têm apenas um filho.

Com relação aos cargos dentro da empresa, os participantes estão distribuídos da seguinte maneira: $32 \%$ dos colaboradores são gerentes; $27 \%$ são analistas; $15 \%$ são assistentes; $10 \%$ são supervisores; $7 \%$ são auxiliares; mais $5 \%$ são diretores e $4 \%$ dos colaboradores entrevistados são coordenadores. De acordo com os dados apurados sobre o tempo de permanência que os colaboradores têm dentro da empresa: um percentual pequeno de colaboradores, 9\%, se encontra em uma faixa de tempo de serviço considerável dentro da empresa, de 21 a 60 anos. Por outro lado, o maior percentual de colaboradores, $34 \%$, informam ter pouco tempo dentro da empresa, entre 2 a 5 anos.

Um dado interessante entre a relação função e tempo de permanência é a seguinte: a função em que os colaboradores têm mais tempo de empresa é a de supervisor, cuja média é de 21 anos, muito acima das demais funções. Seguem-se depois os seguintes dados: os diretores têm em média 10 anos de casa, os gerentes e assistentes possuem 9 anos em média de empresa, os analistas 7 anos e os auxiliares permanecem na empresa, em média, por 3 anos.

\section{Análise e descrição do Capital Intelectual}

O Capital Intelectual da empresa pesquisada foi avaliado por meio de 3 fatores: o Capital Humano, o Capital Estrutural e o Capital Relacional. O Capital pior avaliado foi o Humano, obtendo uma média de 3,3, seguido do Capital Relacional e do Capital Estrutural, ambos com média 4,0. Os dados levantados atestam um nível de adequação maior em relação ao Capital Estrutural, principalmente no que se refere ao uso efetivo do conhecimento e aos investimentos em tecnologia da informação. Por outro lado, os 
números coletados sobre o Capital Humano revelam que os colaboradores da empresa não identificam os mesmos investimentos nessa área.

Tais dados corroboram os achados do estudo de Marques e Gomes (2011) que ressaltaram a necessidade da empresa se atentar para seu capital humano ao considerarem que as pessoas são geradoras de valor organizacional e não meros recursos.

Com relação às iniciativas para o desenvolvimento do Capital Humano, o fator melhor avaliado foi o de investimento em treinamento, com média de 3,7 ( $\mathrm{DP}=0,9)$, o que sugere que a organização disponibiliza recursos para a realização de cursos de capacitação e graduação. Os colaboradores, 59\% deles, concordam que a empresa oferece condições para trabalhador participar de treinamentos voltados para o desenvolvimento de habilidades de liderança e planejamento, oportuniza participação em palestras, debates, workshops e seminários educativos para melhor atender o cliente. $\mathrm{O}$ fator Educação formal, que reconhece a disponibilidade da empresa em oferecer incentivos para a realização de cursos de capacitação e graduação, apresentou média de 3,4, (DP = 1,0); esse fator foi considerado em segundo lugar na avaliação dos colaboradores, juntamente com o fator satisfação que obteve média de 3,4 (DP = 5,0). Sobre a adequação dos colaboradores para com a organização, há um consenso de que a empresa trabalha razoavelmente ou bastante $(69 \%)$ para que isso aconteça.

O Espírito de equipe, fator que avalia a motivação dos colaboradores em inovar nos seus respectivos setores com iniciativas criativas e em participar de atividades que contribuem para manter a integração entre os funcionários, recebeu média de 3,2, com mediana 3,0, mínimo1,0 e máximo 5,0 (DP = 1,1). Da mesma forma, o fator Estabilidade obteve média 3,2 (DP $=1,0)$, com apenas $36 \%$ dos colaboradores afirmando que há políticas de investimento na estabilidade deles dentro da empresa, o que mostra uma fragilidade maior no que se refere ao sentimento de pertencimento e permanência dos seus colaboradores. Esses dados sugerem que é necessária uma política que proporcione maior envolvimento e participação dos colaboradores no dia a dia da empresa, fazendo com que eles se sintam partícipes das decisões e dos seus resultados.

O fator pior avaliado foi o Espírito empreendedor, no qual os funcionários afirmam participar de treinamentos e reuniões constantes que ajudam a desenvolver habilidades de liderança e planejamento e a participarem de atividades que contribuem para manter o espírito de equipe. Esse fator obteve média de 3,1 (DP =1,1), pois na sua maioria, $60 \%$ dos colaboradores, entendem que a empresa pouco, ou razoavelmente, estimula essa prática. Apesar dos colaboradores reconhecerem que a empresa oferece treinamentos, a baixa média no espírito empreendedor demonstra que ela não foca seus esforços na continuidade desses treinamentos, no desenvolvimento de novas lideranças e no estímulo à criatividade do seu quadro de pessoal.

Com relação às Iniciativas para o desenvolvimento do Capital Estrutural, a unanimidade das respostas se encontra no critério do uso efetivo do conhecimento existente, com média 4,6 e mediana 5,0, mínimo 1,0 e máximo 5,0 ( $\mathrm{DP}=0,7)$. A grande maioria dos colaboradores $(65 \%)$ entendeu que a empresa aplica totalmente nos métodos internos de divulgação das informações, como os quadros de avisos, sites, jornais internos etc. $\mathrm{O}$ segundo fator mais bem avaliado foram os Investimentos em tecnologia da informação, com média de 4,2, mediana 4,0, mínimo 1,5 e máximo 5,0 (DP =0,9). A maioria dos respondentes, $74 \%$, concorda que a empresa faz constantes investimentos em redes, servidores e técnicas que auxiliam o armazenamento das informações. Da mesma forma, há um consenso entre os colaboradores, $72 \%$ deles, de que a organização investe bastante ou totalmente nos seus Ativos de infraestrutura, obtendo média 4,0, conservando, 
de maneira satisfatória, suas máquinas, equipamentos de informática e locais de trabalho. Sobre os Mecanismos de transmissão do conhecimento, a média obtida foi de 3,8, mediana 4,0, mínimo 1,0 e máximo 5,0 (DP =0,9), sendo que $61 \%$ dos funcionários acreditam que a organização investe bastante nessa estratégia, mantendo tradições, valores e normas que são compartilhados dentro da empresa.

Com relação aos Processos desenvolvidos pela empresa para auxiliar seus colaboradores na execução de suas tarefas, a média foi de 3,6, mediana 4,0, mínimo 1,0 e máximo 5,0 ( $\mathrm{DP}=1,0)$; nesse fator, a maioria dos respondentes, $62 \%$, afirmam que a empresa se preocupa com essa atividade. Por outro lado, o fator pior avaliado do Capital Estrutural foi Alinhamento do conhecimento com a estratégia, pois apenas 51\% afirmam que a empresa possui mecanismos adequados e eficientes para que os colaboradores possam aplicar seus conhecimentos na solução de problemas que favoreçam a qualidade do trabalho, o que demonstra que a empresa não proporciona a participação dos colaboradores nas reuniões mais frequentes para tomadas de decisões coletivas, embora os líderes estabeleçam metas e planejamentos com os funcionários com vistas ao desenvolvimento da organização. A média obtida nesse fator foi de 3,6, mediana 4,0, mínimo 1,0 e máximo 5,0 (DP =0,9). Entretanto, para chegar em um grau de excelência nesse aspecto, apenas 33\% dos seus colaboradores entendem que ela chegou a esse nível.

Sobre as Iniciativas para o desenvolvimento do Capital Relacional, o fator melhor avaliado nesse capital foi o que corresponde à Marca da Holding, obtendo uma média de 4,4, mediana 5,0, mínimo 1,5 e máximo 5,0 ( $\mathrm{DP}=0,8)$; entre os funcionários, 47\%, afirmam que a empresa transmite confiança e é bem aceita pela clientela. Com relação às Parcerias e alianças estratégicas, a média ficou em 4,2, a mediana em 5,0, mínimo 1,0 e máximo 5,0 $(\mathrm{DP}=0,9)$ e 78\% dos respondentes afirmam que a empresa aplica totalmente essa estratégia, utilizando-se de instrumentos internos de avaliação dos colaboradores e atualização dos sistemas informatizados. De acordo com $59 \%$ dos colaboradores, a organização reconhece que a Satisfação do cliente se encontra em primeiro lugar, sendo que a média desse fator ficou em 3,9, a mediana em 4,0, mínimo 1,0 e máximo 5,0 (DP $=1,1)$. A preocupação com o Market share também se traduz numa marca da empresa, mostrando que a maioria das respostas (38\%) está totalmente de acordo com a política da organização. A média desse fator foi de 3,8, mediana 4,0, mínimo 2,0 e máximo 5,0 (DP $=1,3)$. O relacionamento com os clientes no Auxílio após o serviço prestado recebeu média 3,8, mediana 3,5, mínimo 2,0 e máximo 5,0 (DP = 1,1) e obteve a aprovação de $39 \%$ dos colaboradores que afirmam que a empresa está totalmente voltada para essa questão. $\mathrm{O}$ fator Lealdade dos clientes foi o último avaliado obtendo média de 3,7, mediana 3,5, mínimo 2,0 máximo 5,0 (DP = 1,1). Entretanto, no critério de contatos frequentes com o cliente, há consenso de que a organização mantém um ótimo relacionamento com os seus clientes, quando $80 \%$ dos colaboradores afirmam que há bastante ou total contato da organização com os seus clientes.

De acordo com Stewart (1998), o Capital Relacional refere-se aos relacionamentos contínuos com as pessoas e organizações para as quais a empresa vende os seus produtos e serviços. Nesse sentido, os dados permitem afirmar empresa estudada preocupa-se com a sua imagem externa junto aos clientes, em essencial no que diz respeito às parcerias, alianças estratégicas e à valorização da sua marca, fatores bem avaliados pelos colaboradores dentro deste fator. 


\section{Análise e descrição da Gestão do Conhecimento}

A Escala de Gestão do Conhecimento, EGC, adaptada por Pais (2014), foi o instrumento utilizado para a avaliação da Gestão do Conhecimento na empresa estudada. Conforme os fatores descritos na escala, seguem os indicadores avaliados e os números obtidos.

O valor médio relativo do fator 1, Orientação cultural para o conhecimento, que reflete as práticas, regras, normas e procedimentos que são instituídos dentro da organização obteve a maior média $(M=4,1)$. Verifica-se um consenso entre os respondentes, pois $77 \%$ dos colaboradores acreditam que a empresa tem cumprido o seu papel de promover mais conhecimento e a disseminá-lo internamente. Nesse fator, os itens "Cada um de nós tem uma função a cumprir" e "Agimos de acordo com certo princípio", obtiveram $87 \%$ de respostas positivas e o item "Agimos de acordo com a forma como estamos organizados" obteve a menor média, com $69 \%$ de aprovação dos colaboradores.

Em segundo lugar ficou o fator 4, Práticas informais de Gestão do Conhecimento, com média 3,7, mediana 3,5 (DP = 1,0). Esse fator refere-se às interações informais que acontecem dentro da empresa e que facilitam a construção do conhecimento interno, que podem ser as atividades em grupo, contatos interpessoais, reuniões, passeios e viagens, treinamento e visitas. Para Pais (2014), é a gestão simbólica do conhecimento que é produzido dentro da organização que é passível de atribuição de sentido por parte dos colaboradores, pois ele emerge do que se faz e se conhece e é construído por meio da prática discursiva informal. Esse fator que revela as interações que acontecem informalmente dentro da organização e que facilitam a construção social do conhecimento. A maioria dos colaboradores (59\%) consideram que falam uns com os outros sobre as funções desempenhadas e a empresa em que trabalham. Essa construção está baseada em uma prática discursiva que se ancora em uma linguagem comum e coletiva, tanto nos diálogos e histórias que trocam durante o trabalho, quanto nas conversas quando casualmente se encontram. Tal prática discursiva compõe uma gestão simbólica do conhecimento que atribui sentido ao que se conhece e ao que se faz e vai construindo o universo coletivo acerca dos acontecimentos organizacionais mais relevantes. Nesse fator, o item mais bem avaliado foi: "Falamos da nossa empresa", com $84 \%$ de aprovação dos colaboradores e o de pior avaliação foi o item "Falamos uns com os outros sobre assuntos que não compreendemos bem", com apenas $45 \%$ de avaliações.

Esse fator traz as interações e a construção social do conhecimento que se realiza por meio da prática discursiva e das compreensões coletivas acerca dos conhecimentos organizacionais mais relevantes (PAIS, 2014). De fato, de acordo com Machado et al. (2015), cada indivíduo, com seus valores, crenças e experiências forma uma rica fonte de conhecimento e os gestores de pessoas dentro das organizações devem oferecer a seus colaboradores a oportunidade de criarem e transferirem o seu Capital Intelectual de forma eficaz e participativa, com o objetivo de proporcionar resultados efetivos para a organização como um todo. Percebe-se que a referida organização adota ferramentas informais de democratização do acesso aos conhecimentos obtidos pelos colaboradores.

Segundo Rodrigues et al. (2015), não importa o meio escolhido pelo gestor, mas o importante é que ele organize, classifique e crie dispositivos para a disseminação do conhecimento adquirido dentro da empresa, convertendo-o e incorporando-o em novos produtos, serviços e sistemas. Tais conhecimentos podem ser criados e expandidos em diferentes momentos de interação social. 
O fator 2, Orientação competitiva, obteve média 3,6, mediana 3,8 (DP =1,1). Esse fator está mais voltado para o exterior da empresa, orientação que está focada na utilização do conhecimento organizacional em uma lógica competitiva, de desempenho comparativo, é a relação da empresa com os seus concorrentes. A maioria dos colaboradores $(56 \%)$ afirmam que estão atentos aos seus concorrentes. O item melhor avaliado foi "O que sabemos é uma "arma" fundamental para ultrapassarmos os nossos concorrentes", com $71 \%$ das avaliações positivas e o pior item avaliado foi: "Sabemos que os nossos concorrentes têm informações sobre nós", com 40\% das avaliações, indicando que a percepção dos colaboradores com relação à visão que os concorrentes têm sobre eles parece não está bem definida.

Sobre o direcionamento competitivo das empresas, Fragoso (2009) chama a atenção para a questão da acirrada concorrência que existe na atualidade e preconiza que fatores como a tecnologia, a informação e os recursos financeiros já não são mais os responsáveis pela garantia de sucesso das organizações, mas que é necessário estabelecer um ambiente de recursos genuinamente originais, particulares, que sejam mais difíceis de copiar. Desse modo, o contexto atual exige pessoas mais bem preparadas, com competências e habilidades diferenciadas para competirem no mercado e, por outro lado, é preciso que as empresas estejam dispostas a oferecer condições ao desenvolvimento dessas competências. Esses elementos relacionados a produção de conhecimento agregam valores para as organizações e se transformam no diferencial efetivo de competitividade entre as empresas.

O fator 3, pior avaliado entre todos, foi o das Práticas formais de Gestão do Conhecimento, que obteve média 3,5, mediana 3,4 (DP $=1,1)$ coloca em discussão a tomada de consciência do que é relevante conhecer e a instituição de algumas práticas que têm como objetivo a criação do conhecimento, sua preservação, partilha e utilização que ocorrem pela incorporação do que se produz e apreende na execução de produtos e serviços. É esse fator que viabiliza a tomada de iniciativa e a inovação dentro da organização. Com relação às práticas formais do conhecimento, $45 \%$ dos colaboradores dizem acreditar que a organização se junta para resolver os problemas e acreditam que passam informações uns aos outros e participam de seminários e conferências. Nessa perspectiva, a mudança e o desenvolvimento da empresa tornam-se possíveis pela tomada consciência do conhecimento detido o que possibilita a viabiliza a tomada de iniciativa, a improvisação e a inovação (PAIS, 2014). Nesse fator, o item melhor avaliado foi "Juntamo-nos em grupo para resolver alguns problemas", com 57\% de avaliações positivas dos respondentes e o item pior avaliado - entre todos os demais da EGC - foi: "São compensados aqueles que partilham o que sabem", revelando que não há uma política de meritocracia dentro da organização para os colaboradores que se dispõem a compartilhar com os seus pares os seus conhecimentos.

Diante dos dados supracitados, é possível observar que demonstram lacunas no que se refere às práticas formais de gestão do conhecimento. De acordo com Pacheco, Scofano, Beckert e Souza (2009), as organizações têm o papel constitutivo de sistematizar informações e dados, além de fomentar um ambiente propício ao aprendizado por meio de ações democráticas e diferenciadas tais como debates, oficinas, incentivo ao aprendizado coletivo etc.

Takeuchi e Nonaka (2008) apontam a importância das organizações apoiarem as atividades criadoras de conhecimento pelos indivíduos e que criem estratégias para sua amplificação, sobretudo por meio da interação contínua entre o conhecimento explícito, que é formal e sistemático e o tácito que é pessoal e individual. De acordo com tais 
autores, o maior desafio da gestão de conhecimento é tornar o conhecimento tácito em explicito, disponível para todos membros da organização o que pode acontecer por meio de quatro modos de conversão: socialização (compartilhar e criar conhecimento tácito por meio da experiência direta); externalização (articular conhecimento tácito por meio do diálogo e reflexão); combinação (sistematizar e aplicar o conhecimento explícito e a informação) e internalização (aprender e adquirir novo conhecimento tácito na prática).

Cabe ressaltar que existe um modelo de conceitualização e de operacionalização da Gestão do Conhecimento que pode ser integrado aos seguintes processos a serem implementados na organização da pesquisa, conforme Pais (2014), e que envolvem: criação e aquisição - que podem ser agregados pelos novos colaboradores e ampliados pelas parcerias externas; atribuição de sentido: trata-se da compreensão de todos os eventos que acontecem dentro da empresa; partilha e difusão: é a propagação e a expansão do conhecimento dentro da organização, por meio de reuniões de trabalho, nas atividades de formação, nas rodas de conversa, nas pausas para o cafezinho e nas trocas de experiências; memória organizacional: é o armazenamento do conhecimento organizacional que se propaga interna e externamente; medição e recuperação: trata-se das diversas fases do conhecimento organizacional e criação, a identificação, transformação e validação.

\section{CONSIDERAÇÕES FINAIS}

Considerando o Capital Intelectual como um ativo que diz respeito à soma de tudo que todos em uma empresa conhecem e que confere à organização sua vantagem competitiva, a pontuação no que se refere ao capital humano sugere ponto de reflexão, visto que as pessoas não devem ser concebidas no mesmo nível que os demais recursos organizacionais, ou seja, entendem que pessoas não são recursos e sim geradoras de valor. Ressalta-se a importância das empresas pensarem formas de ativamente reter e gerenciar o capital humano que é um recurso altamente competitivo das organizações. Sendo assim, uma gestão do conhecimento não se resumiria em investimentos em tecnologia e gerenciamento de inovação, mas pelo reconhecimento de necessidades individuais e coletivas interdependentes aos processos de criação e aprendizado.

Ressalta-se a relevância da implantação estratégica de uma gestão com foco no conhecimento que incentive a criação e compartilhamento de conhecimento interno, atualização do conhecimento, aplicação do conhecimento para algum benefício da empresa, reutilização do conhecimento, criação de novos conhecimentos etc. que sejam essenciais para o negócio e que apoiem a consecução de objetivos organizacionais e possam agregar valor a clientes internos e externos.

Algumas limitações do estudo podem ser mencionadas: a pesquisa foi aplicada em uma empresa de um segmento muito específico de modo que não se pode generalizar os resultados para empresas de outros segmentos. Além disso, a abordagem estritamente quantitativa do estudo inviabiliza uma compreensão qualitativa aprofundada dos fatores avaliados pelos instrumentos.

A metodologia utilizada para a avaliação da Gestão do Conhecimento não tem por objetivo contemplar um painel completo de medidas e indicadores pesquisados dentro da holding aqui estudada. Um sistema de avaliação dessa amplitude ainda não se apresenta estratégica e metodologicamente possível. O que se buscou foi utilizar um caminho conhecido tendo como instrumento de avaliação a Escala de Gestão do Conhecimento, EGC, proposta por Pais (2014), com a finalidade de proporcionar alguns indicadores para 
que os gestores desta, e de outras organizações, possam se instrumentalizar na busca de melhores estratégias na Gestão do Conhecimento. Nesse caso, a metodologia trabalhada pode servir como um referencial, a partir de uma proposta, ou formato, que melhor convenha a cada empresa, uma vez que ainda nos encontramos em "face da real impossibilidade de se elaborar um modelo de divulgação e avaliação da gestão do conhecimento verdadeiramente universal, que abarque todas as organizações" (COLAUTO; BEUREN, 2003).

Muitas são as possibilidades de reorientação dentro de uma organização para que a Gestão do Conhecimento possa ser realizada de maneira a direcionar a necessidade de desenvolver metodologias nas quais haja o alinhamento estratégico dos processos, o mapeamento do conhecimento individual, a mudança cultural e organizacional. Machado et al. (2015), por exemplo, elencam uma série dessas possibilidade, tais como: o alinhamento dos processos estratégicos ao desenvolvimento dos projetos que visam a valorização do Capital Intelectual; a realização do mapeamento periódico do conhecimento para o crescimento, desenvolvimento e a sobrevivência da organização nessa nova Era da Informação; a priorização do Capital Intelectual como a principal fonte de vantagem competitiva para as organizações atuais; a importância de manterem-se atentos à gestão de mudanças e transformações e a criação de Universidades Corporativas que possibilitem o desenvolvimento dos colaboradores, fazendo com que haja um trabalho colaborativo e multidisciplinar.

Para tanto, sugere-se também que novos estudos sobre o tema possam ser realizados com vistas a identificar os gargalos que existem na identificação e permanência do Capital Intelectual dentro da holding pesquisada, além de promover a busca por uma prática eficaz da sua Gestão do Conhecimento.

Conclui-se pela relevância de se considerar o conhecimento, enquanto um ativo intangível, fonte de vantagem competitiva para as organizações e que esforços decorrentes da avaliação do capital intelectual possibilitem uma formulação de políticas organizacionais que concebam as práticas de gestão do conhecimento alinhadas à estratégia do negócio.

\section{REFERENCIAS}

ALAVI, M.; LEIDNER, D. Knowledge Management Systems: Issues, Challenges, and Benefits. Communications of the Association for Information Systems, v. 1, p. 1-37, 1999.

ALAVI, M.; LEIDNER D. E. Management and knowledge management systems: conceptual foundations and research issues. MIS Quarterly, v. 25, n.1, p. 107-136, 2001.

ALVESSON M.; KARREMAN, D. Odd couple: making sense of the curious concept of knowledge management. Journal of Management Studies, v. 38, n.7, p. 995-1018, 2001.

ALVES, A. C. et al. Análise e mensuração da Gestão do Conhecimento e do Capital Intelectual nas organizações: estudo de caso em uma empresa de contabilidade. Revista Pensamento e Realidade, v. 29, n.4, p. 22-41, 2014. 
ARGOTE, L., MCEVILY, B.; REAGANS, R. Managing knowledge in organizations: an integrative framework and review of emerging themes. Management Science, v. 491, n. 4, 571-582, 2003.

ARMOS, S. Mensuração do Capital Intelectual: estudo de caso na empresa Converge - Tecnologias de Gestão, empresa de prestação de serviço em consultoria e treinamento. Tese de doutorado, Faculdade de Ciências Econômicas da Universidade Federal do Rio Grande do Sul. Porto Alegre, RS, 2003.

BIANCHINI, J.; GONÇALVES, R. B.; ECKERT, A.; MECCA, M. S. Holding como ferramenta de sucessão patrimonial: um estudo sob o ponto de vista da assessoria contábil. Revista de Administração, Contabilidade e Economia da Fundace, v. 5, n. 2, p. 1-14, 2014.

BROWN, J. S.; DUGUID, P. Knowledge and organization: a social-practice perspective. Organization Science, v. 12, n. 2, p. 198-213, 2001.

COLAUTO, R. D.;BEUREN, I. M. Proposta para avaliação do conhecimento em entidade filantrópica: o caso de uma organização hospitalar. Revista de Administração Contemporânea, v.7, n.4, p.163-185, 2003.

DAVENPORT, T. H. Saving IT's Soul: Human Centered Information Management. Harvard Business Review, v. 72, n. 2, p. 119-131, 1994.

DAVENPORT, T. H.; DE LONG, D. W.; BEERS, M. C. Successful Knowledge Management Projects. Sloan Management Review, v. 39, n. 2; p. 43-57, 1998.

DUTRA, J. S. Desenhando programas de desenvolvimento a partir da identificação de competências essenciais. In: M. Eboli (Org.), Coletânea Universidades Corporativas: Educação para as empresas do século XXI (pp. 136-147). São Paulo: Schmukler, 1999.

DZINKOWSKI, R. The measurement and management of intellectual capital: an introduction. Management Accounting: Magazine for Chartered Management Accountants, v. 78, n.2, p. 32-36, 2000.

DUFFY, D. Uma ideia capital. São Paulo: HSM Management, 2000.

EDVINSSON, L.; MALONE, M. S. Capital Intelectual. São Paulo: Makron Books, 1998.

FEITOSA, M. de O. Importância do capital intelectual em uma Instituição de Ensino Superior de uma cidade do Nordeste Brasileiro. Dissertação (Mestrado em Administração) - Universidade Potiguar, Natal, 2015. 
FRAGOSO, S. de A. Gestão estratégica de pessoas como fonte de vantagens competitivas nas organizações. REBRAE. Revista Brasileira de Estratégia, v. 2, n. 3, p. 307-315, 2009.

GOMES, A. V. Análise e mensuração da gestão do conhecimento e do capital intelectual nas organizações: estudo de caso em uma empresa de contabilidade. Trabalho de Conclusão de Curso (Graduação em Administração), Centro de Ciências Sociais Aplicadas da Universidade Federal da Paraíba, 2014.

GRACIOLI, C. Impacto do capital intelectual na performance organizacionalDissertação (Mestrado em Administração), Universidade Federal de Santa Maria, Rio Grande do Sul, 2005.

GREGOLIN, F. O capital intelectual como fonte de vantagem competitiva. Revista Sapere, v. [nd], n. [nd], p. 63-72, 2016.

MACHADO, E. S. Capital Intelectual e Gestão do Conhecimento: desafios dos gestores de Recursos Humanos diante dos novos contextos de gerenciamento. Revista de Ciências Gerenciais, v. 19, n. 30, p. 3-9, 2015.

MARCZYK, G., DEMATTEO, D., FESTINGER, D. Essencials of research design and methodology. New Jersey: John Wiley \& Sons, Inc., 2005

MARQUES, R. O.; GOMES, A. V. Análise de indicadores de capital intelectual: estudo de caso em uma empresa atacadista. Revista Administração em Diálogo, v. 13, n. 3, p. 69-90, 2011.

MOREIRA, F. G.; VIOLIN, F. L.; SILVA, L. C. Capital intelectual como vantagem competitiva: um estudo bibliográfico. Revista de Carreiras e Pessoas, v, 4, n. 3 p. 296$311,2014$.

NASCIMENTO, A. do. Capital intelectual: formas de avaliação e métodos de mensuração. Revista Interdisciplinar Científica Aplicada, v.1, n.3, p. 1-15, 2008.

PACHECO, L.; SCOFANO, A. C.; BECKERT, M.; SOUZA, V. Capacitação e desenvolvimento de pessoas. 2. ed. Rio de Janeiro: Editora FGV, 2009.

PAIS, L. Gestão do Conhecimento. In: SIQUEIRA, Mirlene Maria Matias (Org.). Medidas do comportamento organizacional: ferramentas de diagnóstico e de gestão. São Paulo: Artmed, 2014.

PIRES, L. A. D.; MENEGASSI, C. H. M.; TATTO, L. Gestão do Conhecimento e capital humano: uma revisão sistemática de literatura. Revista Conbrad, v.1, n.3, p. 204-220, 2016. 
RODRIGUES, G. da C.; OLIVEIRA, T. A. A. de; NERY, I. C.; SOUZA, B. L. de. Gestão do conhecimento: avaliação das dimensões, o estudo de caso das práticas de um setor de tecnologia da informação de uma instituição pública federal. Anais do IV Simpósio Internacional de Gestão de Projetos, Inovação e Sustentabilidade. São Paulo, 2015.

STEWART, T. A. Capital Intelectual: a nova vantagem competitiva das empresas. Rio de Janeiro: Campus Ltda., 1998.

TAKEUCHI, H.; NONAKA, I. Gestão do conhecimento. Porto Alegre: Bookman, 2008. 